\title{
FORM AND FUnCTION OF CONDITIONAL CONSTRUCTIONS IN THE GUMUZ LANGUAGE OF MeteKel ZoNe
}

\author{
Travis Williamson and Eric Larson \\ SIL Ethiopia
}

\begin{abstract}
This paper describes not only the forms of the limited number of conditional constructions in Gumuz [guk] but also their various functions as found primarily in natural texts collected from a variety of districts within Metekel Zone in northwestern Ethiopia.
\end{abstract}

Keywords : conditional, Gumuz, Kumuz

The breadth of the Gumuz territory in Western Ethiopia and the high cultural value of maintaining identity with one's father's clan, have had great impact on the Gumuz language resulting in the development of diverse yet thus far sustainable dialect variation. Cutting East to West through the region, the Blue Nile River carves a natural divide not only between political zones, but also between linguistic dialects centers (Ahland 2004). Data for this study comes from more than 20 natural texts, both narrative and hortatory, collected from five districts of Metekel zone north of the Blue Nile. ${ }^{1}$

\section{Form}

The basic structure of conditional constructions in the Gumuz language of Metekel zone is quite consistent, showing only minor variation across their various uses. The apodosis (Q) is always preceded by the protasis $(\mathrm{P}),{ }^{2}$ thus aiding the listener by mirroring the logical sequence of events implied in the construction (the condition described in the protasis must be met prior to the main statement of the apodosis).

1 The majority of our data and research is from the Mandura district, the political capital of Metekel zone. But some of the texts were collected from Dangur, Dibate, Bulen, and Wembera districts. For more on Gumuz dialect variation and distribution, see Ahland (2004). All examples have been given in the approved orthography for the Gumuz language.

2 We have found only one exception to this rule, as is noted later in the paper (example 31). 
(1)
[k-aa-w-e
a-mad'uuma
na-manasa-ça-aya]P
COND-3SG.NFUT-come-TWRD NOM-sickness LOC-bad-CL:eye-water

$\begin{array}{lll}\text { [eta-ma-gam-aça-Saainsa } & \text { d-e-gam-aa-ts } & \text { tisok'w } \\ \text { REL-NMLZ-know-CL:eye-science } & \text { AFF-FUT-know-3SG-CL:body } & \text { first }\end{array}$

$\begin{array}{llll}\text { d-e-kaañ-aa-ka } & \text { daa-li-mas'a } & \text { ala-má, } & \text { e-f-ow-aango]Q } \\ \text { AFF-FUT-prohibit-3SG-COM } & \text { REL-belly-house } & \text { GEN-3SG.POSS } & \text { FUT-drink-3PL-NEG }\end{array}$

'If a sickness comes from bad water, the one who knows science will see it first, prohibit his family, and they will not drink it.'

(2)
[k-aça-kaal-aaç
mangisha
COND-2PL.NFUT-be.able-2PL
speak.INF
$\begin{array}{ll}\text { [d-ey-aanzah-aça } & \text { ka-maahamaama]Q } \\ \text { AFF-FUT-be.equal-2PL } & \text { COM-3PL.PRO }\end{array}$

ka-sa-Shuwa]P

INS-mouth/language-Amhara

'If you are able to speak Amharic, you will be equal to them.'

1.1. Protasis. As noted in existing literature on Gumuz conditionals (Ahland 2012: 435-436; Innocenti 2010: 110-111), the verb in the protasis of a Gumuz conditionals is formed with the conditional prefix $k$ - ( $g$ - in some of the other dialects) followed by the subject agreement marker common to the non-future tense. ${ }^{3}$ This $k$-+non-future verb form is consistently used in all the protases of the Mandura dialect. However, we learned from one natural text from the Dibate district and upon further research, that it is possible to use a $g-+$ future form. Example (3a), taken from this Dibate text, shows the advice given by a concerned mother rat to her son who has been playing with a kitten. The first sentence is as it occurred in the story. When asked about the form found in the second sentence of (3a) that is the, $g$-+non-future form, all the respondents agreed that this form was also correct with no variation in meaning. However, in the dialect of Gumuz spoken in the Mandura district, as seen in examples (3b), only the first sentence, with the $k$ - + nonfuture form, was accepted. This may be due to the different ways in which the two dialects form the future tense. ${ }^{4}$

3 For the sake of simplicity and consistency with existing literature, we have followed Ahland's (2012: 231) basic tense distinction between future and non-future. However, although not the focus of this paper, we feel it is important to add a small note on tenses. The Gumuz language reveals a worldview oriented much more spatially than temporally (a topic for another paper), and thus Ahland's temporal distinction feels out of place. It is our experience and findings that the "future tense" is commonly used in circumstances of uncertainty, leading us to see more evidence for a modal distinction between realis and irrealis (Payne 1997: 244). For example, when I ask a waiter if there is any cold Fantu, he may respond with the 'future' tense, dewota 'there will be.' The waiter isn't telling me that he expects the cold Fantu to exist sometime in the future. Rather, the waiter uses this form to communicate that he is uncertain. Examples such as this suggest a classification of this verb form within the irrealis mood, more specifically labelled as 'potential' (Payne 1997: 245). It is easy to understand why this form would then be used for future events as well as in the conditioned clause of an apodosis. With this said, there are arguments against a primary split between realis/irrealis, such as the use of the realis form (non-future tense) in interrogatives and forming the basic conditional verbs. More research is needed in this area.

4 The future tense form used in Dibate closely resembles the form Ahland described as an 'uncertainty' marker (2012: 230). However, given that their conjugation paradigms are different, their historical relationship is questionable and therefore, in need of more research. 
(3) a. Gadetsaam jinda, dadeshok'w ama! Gaatsaam jinda, dadeshok'w ama!

b. Kaatsaam jinda, deshaak'w ama! *Ketsaam jinda, deshaak'w ama!
'If you will go again, he will kill you!' (g-+future)

'If you go again, he will kill you!' (g-+non-future)

'If you go again, he will kill you!' (k-+non-future)

* (k-+future is not possible)

One minor variation in the form of the protasis is to conjugate the verb of presence wot using the $k$-+non-future form, followed by a relative clause stating the condition that must be met, as seen in example (4). For most speakers, this construction can be used interchangeably with the more simplified, single-verb protasis described above, though this longer construction seems to give more weight to the protasis, possibly adding more doubt that it will be met. For this reason, some speakers prefer this form in counterfactual conditions.

(4)

$\begin{array}{lllll}\text { [k-aa-wot } & \text { ee-d-aa-mic-ok'w } & \text { a-gotaha }] P & \text { [manasa-da } \\ \text { COND-3SG.NFUT-be } & \text { like-AFF-3SG.NFUT-defeat-CL:head } & \text { NOM-rabbit } & \text { bad-thing } \\ \text { al-aa-wot } & \text { na-eba } & \text { na-ga, } & \text { na-eba-gotaha, } & \text { ek-aa-wot-aaygo]Q } \\ \text { REL-3SG.NFUT-be } & \text { LOC-village } & \text { LOC-here } & \text { LOC-village-rabbit } & \text { HYP-3SG-be-NEG }\end{array}$

'If it happened that the rabbit had won, the bad things that are here in the rabbit's village, they would not be.'

1.2. Apodosis. The apodosis of Gumuz conditional constructions shows much more variety than the protasis and often it is the verb form used in the apodosis which determines the sentence's specific function (hypothetical, directive, counterfactual, etc.). The most common verb form used in the apodosis is the future tense as in examples (1)-(3) above. The future tense in Gumuz is commonly used to express an action not known to the speaker to be reality. So also, Gumuz conditional constructions, as will be discussed later in 2.1, cannot be used to express known reality.

In addition to the use of future tense verb form in the apodoses, it is not uncommon to find verbs conjugated in the non-future tense, as well as in various clause types: hypothetical, imperative and interrogative. Each of these forms plays an important role in differentiating the specific function of the conditional clause, and will be discussed separately under their respective functions.

The apodosis is most often juxtaposed to the protasis without the need for any connective. However, in many cases, the connective nagana 'then' (lit. 'in that' or 'from that') can be used without disrupting the meaning. It seems that the use of nagana strengthens necessity of the protasis as a prerequisite from which the main clause follows. The following example comes from the Dibate dialect and thus uses the $g$ - prefix instead of $k$ - and naah instead of the Mandura form nagana: 


(5) $[$ g-aa-w-e mbaand
COND-3sG.NFUT-come-TWRD two
na-koleja]Q
Loc-college
'If (a score of) 2.2 comes, then I will study in college.'

1.3. Complex Conditional Constructions. In general, Gumuz discourse structure prefers to leave much information implicit. And so, in a discourse where multiple events are dependent upon one single presupposed condition, there is no need to repeat the protasis with each new clause, thus resulting in multiple apodoses, often stretching for full paragraphs.

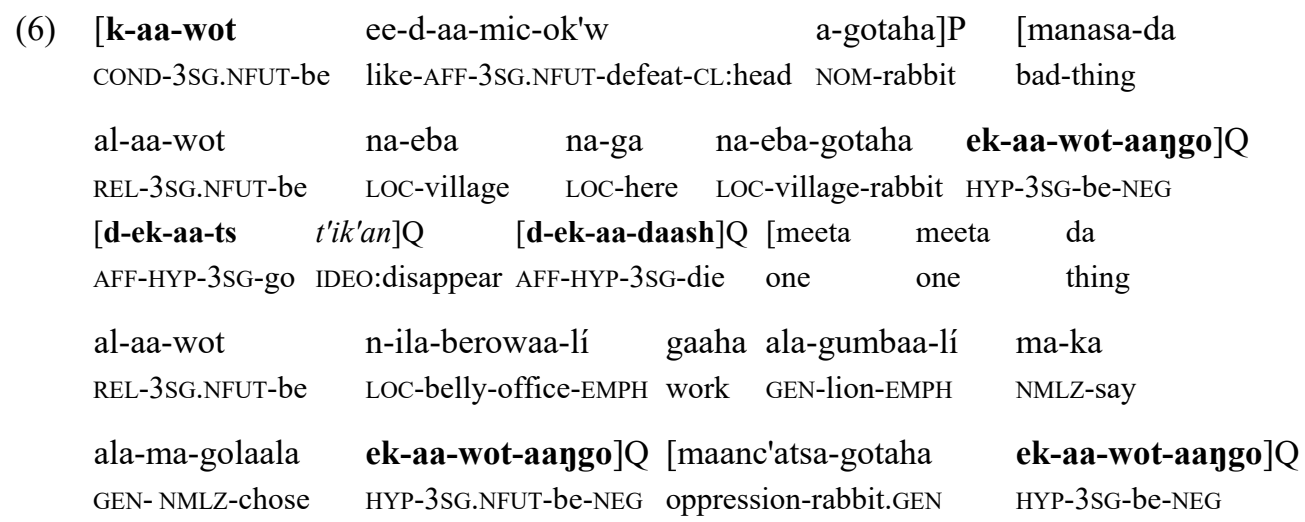

'If it happened that the rabbit had won, the bad things that are here in the rabbit's village, they would not be, they would disappear, they would die. Even some of the things in the offices, even the work of the lions, meaning the election, they would not be. There would be no oppression of the rabbits.'

In instances of multiple apodoses, the eventual repetition of the protasis functions as a clear discourse marker, setting apart a new section or paragraph in the speaker's argument.

When one single event is dependent upon multiple conditions first having been met, it is not uncommon to find multiple protases. These protases can either be juxtaposed (7) or separated with the additive conjunction jinda 'and/also' (8). Example (7) also shows that other clauses, such as explanatory and reason clauses, can be inserted within the sequence of protases leading up to the main statement in the apodosis. 
(7)

$\begin{array}{llllll}{[\text { k-uu-kod }} & \text { ká-aila } & \text { maabraata } & \text { ziyaala }] P & \text { da } & \text { kooma } \\ \text { COND-3PL.NFUt-buy } & \text { BEN-1PL.EXCL.PRO } & \text { electricity } & \text { now } & \text { thing } & \text { all }\end{array}$

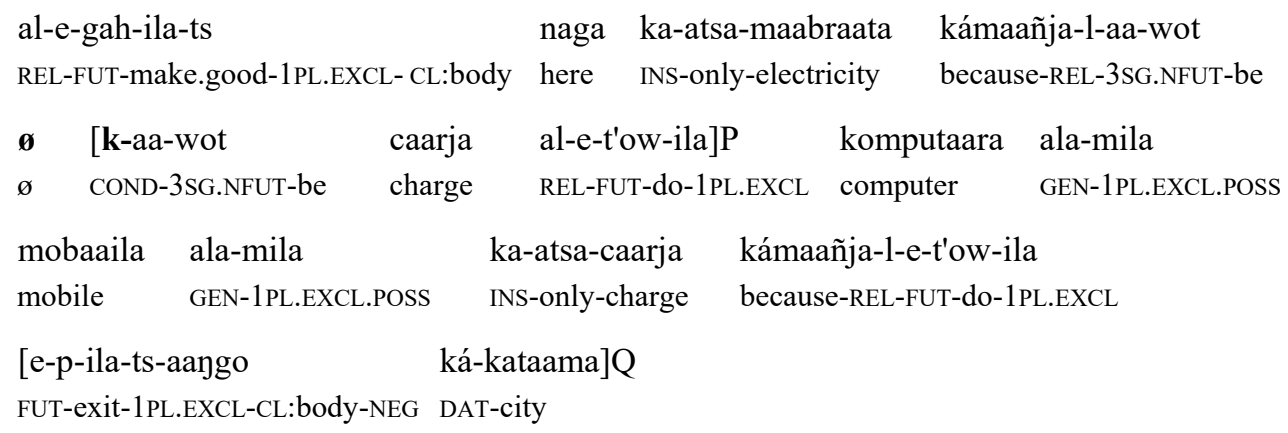

'If they buy us a generator now, since everything that we do is done only by electricity, and if there is charge which we can use, because we will charge our computers and our mobiles, we will not (have need to) go out into the city.'

(8) [Dgisha ala-oba-má $\begin{array}{ll}\text { ala-dagona } & \text { k-aa-bas'-aam } \\ \text { GEN-girl } & \text { COND-2SG-leave.behind-2SG }\end{array}$

word GEN-father-3SG.POSS GEN-girl COND-2SG-leave.behind-2SG

$\begin{array}{llll}\text { m-fey-aa-sh]P } & \text { [jinda } & \text { k-aça-tsohw } & \text { n-ila-caañjaha]P } \\ \text { NOM-accept-2SG- CL:hip } & \text { and/also } & \text { COND-2PL.NFUT-take by force } & \text { LOC-belly-road, }\end{array}$

[ngafa-duwa alana e-gas-iil-aango ygisha al-uwa]Q

female-child DEM.that FUT-hear-CL:belly-NEG word GEN-2SG.POSS

'If you do not respect the word of the girl's father, and if you take her by force on the road, that girl will never obey you.'

Interestingly, while the connective jinda most often introduces an element which is added to what precedes it, it is also found in natural speech to function in a disjunctive sense as in example (9), advice given to a known drunkard. Although the grammar allows for it, readers of this statement in its context do not interpret it as saying, "When you come in the night, if you fall down and break your teeth and if an animal bites you, who will you call?" Rather, the sense is, "If either of these bad things happen to you, who will you call?" Thus the ambiguity between the parallel and disjoined protases is resolved only by context. 
$\begin{array}{lll}\text { (9) nagw-aa-w-e } & \text { n-ila-magaakwa, } & \text { [k-aa-s'iy-aawaaça a-k'os-uwa }] \text { P } \\ \text { TEMP-3sg.NFUT-come-TWRD } & \text { LOC-belly-night, } & \text { COND-3sG-break-CONJ }{ }^{5} \text { NOM-teeth-2sG.POSS }\end{array}$

$\begin{array}{llllll}\text { [jinda } & \text { k-aa-k'ay } & \text { ama } & \text { a-da]P } & \text { [wuli-ça } & \text { e-lak'w-aa-ka-ts-aam]Q } \\ \text { or } & \text { COND-3SG-bite } & \text { 2SG.PRO } & \text { NOM-thing } & \text { who-CONJ } & \text { FUT-ask-2SG-COM-CL:body-2SG }\end{array}$

'When you come in the night time, who will you help you if you (fall) and break your teeth or if an animal bites you?'

In spoken discourse, the linking of protases is not limited by the strong tendency for protases to precede the apodosis on which they are dependent. Example sentence (10) below, immediately follows example (9) above, as the speaker, undeterred by the fact that he closed his sentence with the apodosis in the form of a rhetorical question, added one last clause to his sequence of protases, "Or what if you are beaten by the thieves?" Without an apodosis to finish the thought, this subordinate clause is left hanging, no doubt with a powerful rhetorical effect as the silence of the unfinished sentence implicitly echoes the idea behind the now sandwiched apodosis - "there is no one who will help you!"

\begin{tabular}{|c|c|c|c|}
\hline [jinda & k-aa-b'ac & a-daa-gaakwa & a-al-aa-nshaagw \\
\hline or & COND-3PL.NFUT-hit 2SG.PRO & NOM-people-thief & NOM-REL-3SG.NFUT-roam \\
\hline
\end{tabular}

'Or what if the thieves out walking around at night beat you?' (the apodosis is left implied from previous sentence-_Who will help you?')

\section{Function $^{6}$}

In studying the various forms of Gumuz conditional constructions within the natural spoken contexts, we were able to identify a wide variety of functions; however, our research has also uncovered some definite limitations of usage. Starting from the two-fold classification system as proposed by Thompson, Longacre and Hwang (2007: 255-262) we encountered no problems identifying what they called unreality conditions describing imagined or predicted situations. The Gumuz conditional construction is very much at home here. However, examples of reality conditionals, as defined by Thompson et al, proved much more elusive, and, as we discovered, for good reason.

2.1. Reality Conditionals. One thing we learned early on in our research is that the normal $k$-+non-future conditional construction in Gumuz cannot be used to refer to events or circumstances that are known to have happened. In other words, the Gumuz conditional construction is limited for use only in irrealis situations or events that are in doubt as to whether they have happened. In contexts requiring a reality conditional, or what Taylor (1997) classifies as

5 This suffix -aawaaça functions as a conjunction which foreshadows a negative consequence that will follow the victim.

6 See the introduction to this volume for discussion of the labels given for the various functions of conditional clauses. 
factual, the conditional verb form gives way to the temporal prefix nagw- as seen in present reality construction of example (11). After a hyena stated that he was dying of hunger, the notorious trickster of Gumuz folklore, known as WoDibaagoteya or WoDigotah, said to him:

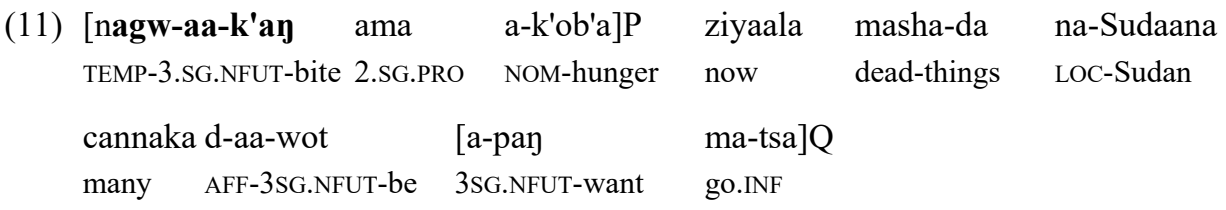

'Since you are hungry, right now there are lots of dead things in Sudan, do you want to go?'

Likewise, past time reality 'conditionals' in Gumuz require the nagw- temporal form in the protasis if the circumstance of the protasis is known to be true. Notice also the non-future tense used in the apodosis, signals the teacher's certainty in what she says.

\begin{tabular}{|c|c|c|c|c|}
\hline (12) & $\begin{array}{l}\text { na-magaazhija } \\
\text { LoC-yesterday }\end{array}$ & $\begin{array}{l}\text { d-ila-tamaar } \\
\text { AFF-1PL.EXCL.NFUT-study }\end{array}$ & $\begin{array}{l}\text { ala } \\
\text { DEM:this }\end{array}$ & $\begin{array}{l}\text { [nagw-aa-wot-aam } \\
\text { TEMP-2SG.NFUT-be-2SG }\end{array}$ \\
\hline & na-gu-mila] & [d-aa-gam-ash-izh & $\mathrm{m}] \mathrm{Q}$ & \\
\hline & LOC-place-1PL.EX & XCL AFF-2SG.NFUT-know-C & :hip-PRF-2 & \\
\hline
\end{tabular}

'We studied that yesterday. Since you were with us, you have learned it.'

However, if the speaker in example (12) was uncertain about whether or not the student was present for yesterday's class, then the conditional construction would be required as seen in example (13) below. This conditional verb form in the protasis immediately classifies the whole statement as irrealis, in this case, hypothetical. The future tense verb form used in the apodosis is required in order to remain consistent with the teacher's uncertainty, but at the same time, the perfect tense/aspect marker $-i z h$ is attached to this future tense verb to portray the event of learning as a completed event, with relevant results for the present context.

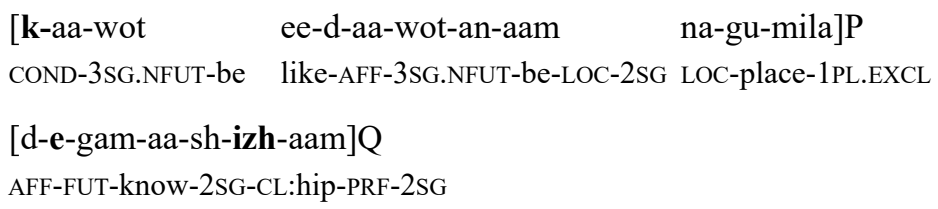

'If you were with us yesterday, you will have learned it.' (possibility, not future)

2.1.1. Habitual/Generic. Along with present and past reality conditionals, Thompson, Longacre and Hwang include a third function of reality conditionals called habitual/generic (2007: 255). Unlike present and past reality, as noted above, the Gumuz language allows habitual or generic statements of truth to be formed using the $k$ - + non-future conditional verb form in the protasis followed by the simple non-future form in the apodosis. The generic truth in (14) applies to all seeds. If the speaker is talking about specific seeds, such as his own as in example (15), then the statement must then have a predictive function (irrealis), thus requiring the verb in the apodosis to be in the future tense. 
(14)
[k-aa-bas'
a-dama
maca]P
[ça-da
a-p-aaygo]Q
COND-3SG.NFUT-leave.behind
NOM-rain rain.INF
seed-thing 3SG.NFUT-sprout-NEG

'If it does not rain, seeds do not sprout.'

(15)
[k-aa-bas'
a-dama
maca]P
[ça-da ala-m
COND-3SG.NFUT-leave.behind
NOM-rain rain.INF
seed-thing GEN-1SG.POSS

e-p-aango]Q

FUT-sprout-3SG.NEG

'If it does not rain, my seeds will not sprout.'

Although the Gumuz language allows for conditional constructions to be used in describing generic truths, it is not required and seemingly not preferred in natural speech. Below are two examples of Gumuz proverbs. ${ }^{7}$ The first, example (16) uses a conditional construction, while the second (17) employs the nagw- temporal construction common to the other realis statements. The difference between conditional form (16) and temporal (17) forms is felt by Gumuz speakers as the conditional creates a hypothetical, or imagined situation. The temporal form communicates an actual situation where porcupines are known to eat people's pumpkins. Both can be understood as proverbs, but the reality vs. unreality difference between them does not go unnoticed by mothertongue speakers.
(16) [k'owa
$\operatorname{dog}$

k-aa-sh-ok'w

mata]P

[a-'iinz-ats-aango]Q

COND-3SG-die-CL:head bird

3SG.NFUT-roast-CL:body-NEG

'If a dog kills a bird, he doesn't cook it.'

\begin{tabular}{|c|c|c|c|}
\hline $\begin{array}{l}\text { [kaaja } \\
\text { porcupine }\end{array}$ & $\begin{array}{l}\text { nagw-aa-s } \quad \text { paatuu-b'aga]P } \\
\text { TEMP-3sG.NFUT-eat pumkin-person.GEN }\end{array}$ & $\begin{array}{l}\text { [na-ja } \\
\text { LOC-tree }\end{array}$ & $\begin{array}{l}\text { a-ka-zhij-aango]Q } \\
\text { 3sG.NFUT-COM-sleep-NEG }\end{array}$ \\
\hline
\end{tabular}

'When (if) a porcupine eats a person's pumpkin, he doesn't sleep with it in a tree.'

2.2 Unreality Conditionals. Unreality conditionals are far more common and more versatile than reality conditionals. Not only do they occur more frequently, but they also show a much broader range of functions, all of which share the same $k$-+non-future in the protasis. This form, as has already been mentioned, indicates an event that is potential rather than actual. In order to differentiate the various functions, special attention must be given to the verb forms found in the apodoses.

2.2.1. Hypothetical and Predictive. The hypothetical and predictive conditional clauses are the most common functions we encountered in our data, such that more than $70 \%$ of the conditional clauses in natural texts are classified here. The apodosis in these clauses always takes a future tense verb, which is to be expected when describing imagined or potential situations. We have

7 These proverbs were recorded and presented as such by Ahland (2012: 433 \& 436). They were modified only with respect to orthography rules. 
already seen examples of hypothetical conditionals: examples (1) and (2) imagined possible good things that an educated Gumuz person could achieve for his/her people, examples (9) and (10) imagined the evils that could befall the drunkard stumbling along the road at night. Likewise, we have already seen many examples of predictive conditional clauses: examples (3), (8) and (15) are clear examples, as well as example (18) below, taken from a Dibate text describing the medical treatment needed for a badly injured baby.
(18) [g-aa-zhij-ok'w
gá-mazhija gá-mbaand]P
[ma-sh-aa-s]Q
COND-3SG.NFUT-sleep-CL:head
DAT-sleeps
DAT-two
FUT-die-3SG-COP

'If he is made to wait another two days, he will die.'

2.2.2. Directive. Directive conditionals are most commonly found in hortatory texts. The verb form of the apodosis of directive conditionals is many times an imperative as in example (19). As with our comments on reality conditionals, the use of the conditional construction to give a command communicates that the speaker is unsure as to whether or not the condition is or will be met, therefore softening the command's force. If for example in example (19), the speaker presumes with confidence that the teachers of God's word are coming, then he would be required to change the conditional form kaawe in the protasis to a temporal future nagwewaae "when he will come.'

$\begin{array}{lll}{[\mathbf{k}-\mathbf{a a}-\mathbf{w}-\mathbf{e}} & \text { a-b'aga } & \text { a-eta-ma-tig-atsa-ygisha-Misa } \\ \text { COND-3SG.NFUT-come-TWRD NOM-person } & \text { NOM-REL-NMLZ-show-CL:body-word-God.GEN }\end{array}$

$\begin{array}{lll}\text { ká-akwa]P } & {[\text { kama-'e-ç-ak'w-aango }} & \text { ygisha-Misa]Q } \\ \text { DAT-1PL.INCL.PRO } & \text { NEG.IMP-refuse-2SG-CL:head-NEG } & \text { word-God.GEN }\end{array}$

'If a teacher of God's word come to us, don't refuse God's word.'

Although direct imperatives are the most common verb forms found in the apodoses of directive conditionals, cohortatives, jussives (20), and rebuke questions (21) can be used to express the imperatival force. Interestingly in our study of the hierarchy of forms used in expressing a command, we found that the rebuke question is the most powerful means of commanding a behavioural change. The speaker in (21) is saying to a known lazy person in the strongest possible way, 'Do not sit idle with it!'
[k-aa-ça-sh
a-jinda
dida-má]P
[n-aa-ça-sh]Q
COND-3SG.NFUT-give-CL:hip NOM-another
children-3SG.POSS JUSS-3SG-give-CL:hip

'If another person sends his children (to school), let him send.'
[k-ar-ç taba ká-ama]P [e-gah-aa-li
COND-1SG.NFUT-give hoe DAT-2.SG.PRO FUT-be.good-3SG-Q
$\begin{array}{ll}\text { nagw-e-'iy-aa-ka-sh-ila-s'ey-aam } & \text { balaash]Q } \\ \text { TEMP-FUT-stand-2sG-CoM-cl:hip-CL:belly-CL:ear-2sG } & \text { empty }\end{array}$

'If I give you a hoe, will it be good when you sit idle with it?' 
2.2.3 Counterfactual. The counterfactual conditional in Gumuz is the only type of conditional that demonstrates a preference toward modifying the protasis, while still maintaining the true conditional sense (unlike the reality conditionals which drop the conditional marker in favour of a temporal marker). As stated above and shown in example (4), repeated below (22), counterfactuals commonly use the verb of presence wot conjugated in the conditional $k$-+non-future form, then followed by a special relative clause. Although some speakers prefer this form, it is not found consistently in the counterfactuals of natural texts.

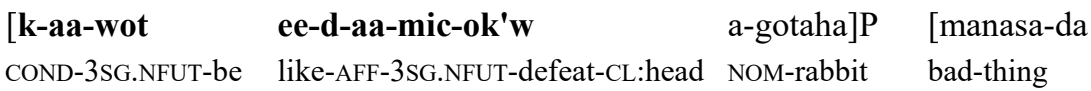

al-aa-wot na-eba na-ga, na-eba-gotaha, ek-aa-wot-aango]Q REL-3SG.NFUT-be LOC-village LOC-here LOC-village-rabbit HYP-3SG-be-NEG

'If it happened that the rabbit had won, the bad things that are here in the rabbit's village, they would not be.'

The apodosis of counterfactual clauses in the Mandura dialect of Gumuz is formed most unambiguously by conjugating the main verb with the prefix, ek-, identified by Ahland as a hypothetical prefix (2012:436). ${ }^{8}$ This form can describe both past events (23) as well as present situations (24). It can also be negated as was seen in example (4). We have found no evidence to support either Ahland's data which suggests the addition of the past tense auxiliary tisok'wa (2012: 436), or Innocenti's identification of a mood-changing suffix -ia on what he has called irrealis, or counterfactual, conditionals (2010: 110-111).
[k-aa-mah-oo-ç
a-daa-It'op'eya
Naaigiriya]P [d-ek-uw-aatish]Q
COND-3SG.NFUT-defeat-PL-CL:eye NOM-people-Ethiopia
Nigeria
AFF-HYP-3PL.NFUT-pass

'If the Ethiopians had defeated Nigeria, they would have advanced (to the World Cup).'

(24)
ziyaala dama d-aa-c
[k-aa-wot
ahwa ala-ça
na-oka]P
now rain AFF-3SG.NFUT-rain COND-3SG.NFUT-be clothes GEN-2PL.POSS LOC-sun
[d-ek-aa-ca-ts]Q
AFF-HYP-3SG.NFUT-rain-CL:body

'It is now raining. If your (pl) clothes had been in the sun, it would have rained on them.'

The hypothetical mood, contrary to the term's broader usage, is defined as "an epistemic mood that signals that the speaker evaluates a proposition as counterfactual, but otherwise possible." (Loos et al, 2004) Accepting this definition's limitation of hypothetical to include only that which

8 Ahland's research records this hypothetical prefix as dega-. However, in both our natural texts and our testing, we found no evidence of voicing in the second syllable's consonant $[\mathrm{g}]$. Rather, the voiceless [k] is much preferred. In addition, as proposed by Ahland (2012: 436, footnote 3), this prefix can be analysed further by recognizing that the $d$ - prefix, described as Uzar (1989: 383) and Ahland (2012: 206) as the affirmative marker is notably absent when negated (4). In addition, the $a$-is the 3SG.NFUT prefix, leaving only the $e k$ - as the basic hypothetical prefix. 
the speaker views as counterfactual, the label fits very well with the Gumuz prefix $e k$-, which can be used not only in counterfactual conditionals, as also in counterfactual statements:

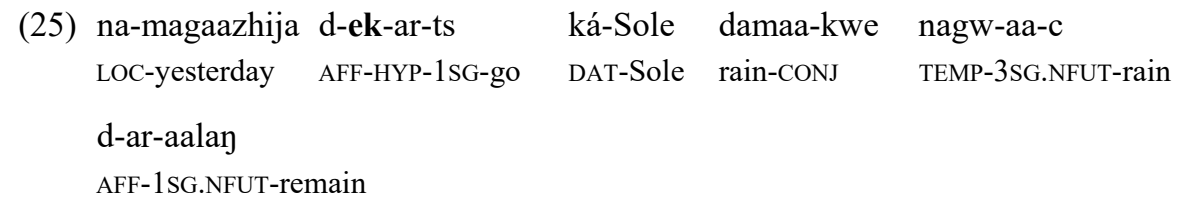

'I would have gone to Sole, but when (because) it rained, I remained.'

Finally, it should be noted that the $e k$ - hypothetical prefix is reportedly used only within a small dialect cluster found in the Eastern part of the Mandura district. Other Gumuz within Mandura, as well as those in Dibate and Dangur would naturally communicate counterfactual conditionals by adding the perfect tense marker -izh onto the verb in the protasis (26). Counterfactuals describing events that would have happened, but didn't, are constructed using a negated form of the negative auxiliary verbs ko 'refuse/refrain' or bas' 'leave behind' in the apodosis. As noted by Ahland (2012: 375-376) these two verbs are commonly used in the negation of subordinate clauses. Negative counterfactuals as in (27) and (28) use these negating auxiliaries conjugated in the negated future tense.

\begin{tabular}{|c|c|c|c|c|}
\hline $\begin{array}{l}{[\mathrm{k} \text {-aa-wot ee-d-aa- }} \\
\text { COND-3sG-be like-AFF- }\end{array}$ & $\begin{array}{l}\text { h-ok'w-izh-aam } \\
\text { G.NFUT-enter-CL:head-PRF-2SG }\end{array}$ & $\begin{array}{l}\text { bac'a } \\
\text { meat }\end{array}$ & $\begin{array}{l}\text { al-uwa } \\
\text { GEN-2SG.POSS }\end{array}$ & $\begin{array}{l}\text { k-íla-mas'a]P } \\
\text { DAT-belly-house }\end{array}$ \\
\hline [e-s-aa-n-aaygo & a-k'owa ]Q & & & \\
\hline FUT-eat-3SG-LOC-NEG & NOM-dog & & & \\
\hline
\end{tabular}

'If you had taken your meat into the house, the dogs would not have eaten it.'
(27) [k-aa-mah-oo-ç-izh a-daa-It'op'eya Naaigiriya]P [e-ko-ow-aango
COND-3SG.NFUT-defeat-PL-CL:eye-PRF NOM-people-Ethiopia Nigeria FUT-refrain-3PL-NEG
ma-atish-owa]Q
NMLZ-pass-3PL

'If the Ethiopians had defeated Nigeria, they would have advanced (to the World Cup).' (Lit. '...they would not have refrained from moving on.')
(28) [k-aa-wot ee-d-aa-bas' a-dama ma-c-aa-zh]P
COND-3SG-be like-AFF-3SG.NFUT- leave.behind NOM-rain NMLZ-rain-3SG-PRF
[e-bas'-ar-aango matsa]Q
FUT-leave.behind-1SG.NEG go.INF
'If the rain had not rained, I would have gone.'
(Lit. '...I would not have refrained from going.').

2.2.4. Logical Conclusion. Although far less common in Gumuz discourse, we have found evidence of conditional constructions used to draw logical conclusions. By this, we mean that the main clause in the apodosis is not necessarily conditioned upon the veracity of the protasis, but 
rather the protasis, if proven true, in turn provides the logical basis on which the statement in the apodosis is proven. For example, in (29), whether the hearer's god is true or false is not directly conditioned upon the survival/death of the baby. Rather, the speaker believes that the potential death of the baby would provide evidence against the reality of the god to whom the hearer prays.

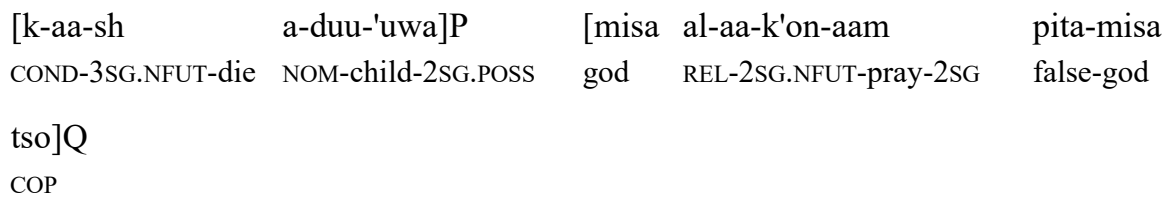

'If your child dies, the god to which you pray is a false god.'

Example (30) was spoken by a doctor while on his way to a house where a child was presumed to be dead. Whether or not the child is dead is not dependent upon the absence of breath. Rather the presence or absence of breath provides evidence on which the doctor will make his conclusion.
[k-aa-'em
a-gashokwa na-lisa-má]P
[d-e-sh-aa-zh]Q
COND-3SG-not.BE
NOM-breath
LOC-mouth-3SG.POSS
AFF-FUT-die-3SG-PRF

'If there is no breath in his mouth, he is dead.'

With both of these examples, it is clear to see that logical conclusion conditionals are not true conditionals in the sense that the apodosis is directly conditioned upon the protasis. Rather, the conditional construction is used in light of an implied speech act verb - speak, know, understand, etc - which would be used to draw the logical conclusion. Example (29) could be stated as a true conditional by saying, "If your child dies, we will know that the god to which you pray is a false god." In this sentence, the act of knowing is directly dependent on the condition set in the protasis. So also, example (30) could be restated "If there is no breath in his mouth, I will proclaim him dead." The doctor's proclamation as such is conditioned upon the absence of breath, and thus a true conditional clause.

2.2.5. Argumentative. The final function of unreality conditionals we found in Gumuz texts is argumentative. These conditions, as with logical conclusion, do not function in a true conditional sense, that is, the apodosis is not truly conditioned upon the protasis. Rather, argumentative conditions function much more like topic-comment, where the protasis raises a topic, on which the apodosis makes a comment. Example (31) was found in a story where a lazy man is notorious for hanging around people's houses during meal times in order to beg for free food. When a woman sees this man she says, "Go home, you are only here to eat my food." The lazy man, taking this hypothetical event of "me eating your food" as his topic, then provides his comment on it, "what is the problem with that?" This example is also the only example we have of the apodosis preceding the protasis - likely preferred in this case because the terse and flippant attitude communicated in the fronted question word, as in the English saying, "So what if I eat your food?" 


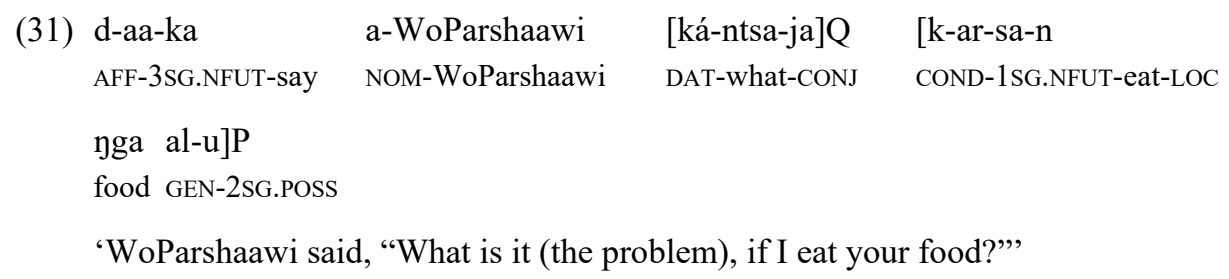

Example (32) is an argumentative conditional in the topic-comment structure. After giving advice on how to take care of one's mobile phone, the speaker relieves himself of any responsibility that may result if his advice is not heeded.

\begin{tabular}{|c|c|c|c|}
\hline $\begin{array}{l}\text { [k-aa-yaar-ok'w } \\
\text { COND-2SG.NFUT-carry-CL:head }\end{array}$ & $\begin{array}{l}\text { mobaaila } \\
\text { mobile }\end{array}$ & $\begin{array}{l}\text { na-'eyaa-uwa]P } \\
\text { Loc-hand-2sG.Poss }\end{array}$ & $\begin{array}{l}\text { [k-uu-tsohw } \\
\text { COND-3PL.NFut-take.by.force }\end{array}$ \\
\hline a-daa-gaakwa]P & & n-ila-n & \\
\hline NOM-people-thief & 1SG.NFUT-b & e-LOC-NEG LOC-belly & 3SG.POSS \\
\hline
\end{tabular}

'If you carry your phone in your hand and thieves grab it, I am not in it (not my fault).'

In another example of an argumentative conditional (33), the protasis is the content of the speakers uncertain knowledge.
[k-aa-wot
ee-d-aa-wot-an-aam
na-gu-mila]P
[ar-zah-aango]Q
COND-3SG.NFUT-be
like-AFF-2SG.NFUT-be-LOC-2SG LOC-place-1PL.EXC 1SG.NFUT-know-NEG

'I do not know if you were with us (yesterday).'

2.3 Concessive. Concessive conditionals are an intriguing category that deserves mention. Functionally speaking, they are not true conditionals because the apodosis is said to be true regardless of whether the condition of the protasis is met. In fact, it is the blatant disregard for the protasis that gives the concessive statement its force. However, with that said, the form of the Gumuz concessive construction is so obviously built upon the conditional verb, that it would be a mistake to exclude them from the list of functions of conditional clauses.

The concessive form in Gumuz is formed by adding the locative suffix onto the end of the normal $k$-+non-future conditional verb as seen below (Ahland 2012: 439-440). Example (34), like the habitual/generic reality conditional, has a present tense force due to the non-future verb form in the apodosis and is thus best translated in the English free translation as 'Even though...'. Example (35) uses a future tense in the apodosis, thus looking ahead toward a future event and translated into English as "Even if..." 
(34)

\begin{tabular}{|c|c|c|c|}
\hline [g-ii-had-an & gá-Woreda]P & [ii-gá-pan-aaygo & eta-ma-c'ak'-asa \\
\hline COND-3PL.NFUt-call-LOC & DAT-district & 3PL.NFUt-BEN-seek-NEG & REL-NMLZ-untie-CL:mouth \\
\hline
\end{tabular}

'Even though he is called to the district meeting, a translator is not sought for him.'

(35)
[k-aa-c-an
a-dama]P
[d-e-ts-okwa
ka-motor]Q
COND-3SG.NFUT- rain-LOC
NOM-rain
AFF-FUT-go-1PL.INCL
INS-motorcycle

'Even if it rains, we will go on the motorcycle.'

Though not required, and not found in the majority of the natural occurrences in our texts, all of our Gumuz co-workers agreed that the concessive meaning is brought out more clearly when the emphasizing suffix - $l i$ is added to the final word of the protasis, as seen in example (36). The addition of $-l i$ is especially helpful given that, in some contexts, the verb's locative suffix alone is not sufficient to communicate the concessive sense.
[k-aa-c-an
a-damaa-lí]P
[d-e-ts-okwa
ka-motor]Q
COND-3SG-rain-LOC
NOM-rain-EMPH
AFF-FUT-go-1PL.INCL
INS-motorcycle

'Even if it rains, we will go on the motorcycle.'

This emphasizing suffix - $l i$ has been labelled by Ahland (2012) as simply a "CONJ" (7.109, 12.82), or in another example "EMPH" (8.23), without further explanation or analysis. Our study of its uses among a variety of speakers has shown that it often communicates the sense of "contrary to expectation/surprise" as well as, many times "completeness/thoroughness." This can be seen in example (37) where the speaker expresses surprise at the extent of which he was robbed. ${ }^{9}$ It is the element of "contrary to expectation" that clarifies the concessive force in the Gumuz concessive constructions.
d-aa-w-e
d-aa-gaakw
bira ala-m
kooma,
AFF-3SG.NFUT-Come-TWRD
AFF-3SG.NFUT-steal
money GEN-1SG.POSS
all

kasha-dida-ça-saant'imaa-lí

COM-small-seed-coin-EMPH

'The thief stole all my money, even the small coins!'

9 So also example (6) above used -li twice when saying, "even some of the things in the offices, even the work of the lions, meaning the election, they would not be." The use of $-l i$ in this context communicates not just an additional change one might expect if the rabbits were in charge, but rather, something contrary to expectation, which then pushes the extent of what will "no longer exist." Thus, given the background of the rabbits complaining after having lost the election, it seems they are referring to what they believe to be a dishonest handling of the election. Surprisingly even that, they claim, would have been done away with if the rabbits would had been put in charge. 
Given that the $k$-+non-future conditional forms must be replaced by the temporal nagw-forms when communicating realis mood, that which is known to be true, so also this nagw-form must be used when forming the known outcomes of past concessive clauses. Likewise, both the locative suffix $-n$ and the emphasizing suffix - li should be added to clearly communicate the necessary surprise of concessive sense. Example (38) gives a past time concessive statement.

\begin{tabular}{|c|c|c|c|c|c|}
\hline \multicolumn{2}{|c|}{ [nagw-aa-bas'-an } & \multirow{2}{*}{$\begin{array}{l}\text { a-Roni } \\
\text { NOM-Rooney }\end{array}$} & \multicolumn{2}{|c|}{ ma-wot-aa-n } & na-maasiyaa-lí]P \\
\hline & ind-LOC & & NMLZ-be- 3 & SG-LOC & LOC-game-EMPH \\
\hline [d-aa-mahooc & a-ma-v & azha-má & Arsenal & $5-0] Q$ & \\
\hline AFF-3SG.NFUT-defeat & NOM-PL- & end-3SG.POSS & Arsenal & $5-0$ & \\
\hline
\end{tabular}

'Even though Rooney did not play in the match, his team defeated Arsenal 5-0.'

\section{Functions of Conditionals within Discourse}

As would be expected, conditional clauses are found most frequently in hortatory and expository texts. When we encountered them in narratives, they are always used in direct discourse, since the irrealis mood of conditional constructions doesn't align well with the Gumuz's preference to tell stories from the $3^{\text {rd }}$ person omniscient voice.

Within hortatory and expository texts, conditional constructions serve two primary functions. First, they occur frequently in the supporting material in order to provide the reason, or basis on which the main argument or command is made. This is true of example (18) above where the doctor is begging the parents to allow him to give treatment to the injured baby. He supports his main point by saying "If he is made to wait two days, he will die." Likewise, the mother rat's advice to not play with the kitten is supported by a conditional clause in example (3) - "If you go again, he will kill you!" Example (7) gives reasons for why this employee requests a generator be purchased for his office. And the multiple protases in examples (9) and (10) give for the drunkard a handful of negative consequences to strengthen the speaker's argument that he should address his drinking problem.

Initially it was surprising to see that the directive conditionals were not used more often to express the main exhortations in hortatory texts; however, this is likely the result of the Gumuz very direct style of confrontation. Conditional clauses, as has been noted elsewhere, always communicate the irrealis mood, meaning there is some level of uncertainty within the mind of the speaker. Stating a main exhortation in a form that is conditioned upon an uncertain protasis would soften its blow and strip it of the force desired in most Gumuz hortatory texts.

The second use of conditional clauses within the discourse structure is that of topic raising. It is possible for the speaker to outline his argument with conditional clauses which set the scene for the next discourse unit. Example (19) above is a directive conditional which shifts the discourse from the speaker's opening expository section in which he describes his Christian beliefs, and then, moving into the hortatory response that he desires to see from his hearers, he says, "If a teacher comes...don't refuse God's word." Here is one instance, where the speaker is intentionally wanting to soften the force of the exhortation, and so using the directive conditional is entirely appropriate. Similarly, within a text defending the need for Gumuz to send their children to school, there is a conditional sentence used to raise the first paragraph of supporting examples, that is, the importance of having someone who knows math (39). 


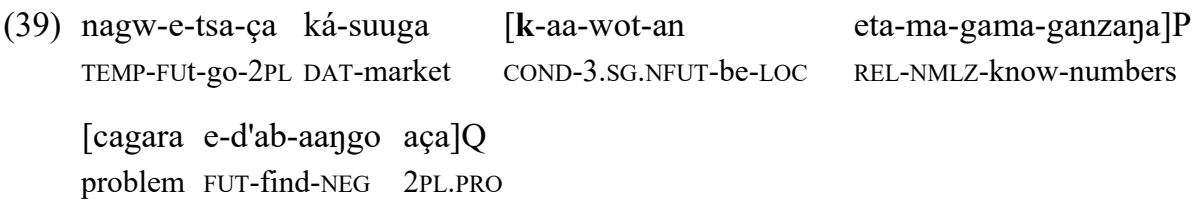

'When you go to the market, if there is someone among you who can count, you will not encounter a problem'

\section{Conclusion}

Our study of conditional clauses in the Gumuz language of Metekel Zone has taken us well beyond the current literature and into detailed analysis not only of the forms, but also of the various functions with which they are used. Our research has confirmed earlier analyses of the conditional verb form $k$-+non-future as being highly productive, especially, as we have observed, in describing unreality conditionals (hypothetical, predictive, and counterfactual events). However, our analysis of this form has consistently proven it to be incapable of introducing reality conditionals where the protasis is known to be true, which, instead, are expressed using a temporal construction with nagw-. Special testing and attention to understanding counterfactual conditionals, we feel, has refined and expanded the existing knowledge of these forms. The same is true of concessive constructions and the previously unanalyzed emphasizing suffix -lí. More research is needed into the relations between tense and mood, though this study on conditionals has been an informative step toward a deeper understanding. 


\section{Abbreviations used}

$\begin{array}{llll}* & \text { Unacceptable form } & \text { INF } & \text { Infinitive } \\ 1 & \text { First person } & \text { IMP } & \text { Imperative } \\ 2 & \text { Second person } & \text { INS } & \text { Instrumental } \\ 3 & \text { Third person } & \text { JUSS } & \text { Jussive } \\ \text { AFF } & \text { Affirmative } & \text { LOC } & \text { Locative } \\ \text { BEN } & \text { Benefactive } & \text { NEG } & \text { Negative } \\ \text { COND } & \text { Condition } & \text { NFUT } & \text { Non-future } \\ \text { CL: } & \text { Classifier } & \text { NMLZ } & \text { Nominalizer } \\ \text { COM } & \text { Comitative } & \text { NOM } & \text { Nominative } \\ \text { CONJ } & \text { Conjunction } & \text { PL } & \text { Plural } \\ \text { COP } & \text { Copula } & \text { POSS } & \text { Possessive } \\ \text { DEM: } & \text { Demonstrative } & \text { PRF } & \text { Perfect } \\ \text { EMPH } & \text { Emphasizer } & \text { PRO } & \text { Pronoun } \\ \text { EXCL } & \text { Exclusive } & \text { Q } & \text { Question Marker } \\ \text { FUT } & \text { Future } & \text { REL } & \text { Relativizer } \\ \text { GEN } & \text { Genitive } & \text { SG } & \text { Singular } \\ \text { HYP } & \text { Hypothetical } & \text { TEMP } & \text { Temporal } \\ \text { IDEO: } & \text { Ideophone } & \text { TWRD } & \text { Toward (directional) } \\ \text { INCL } & \text { Inclusive } & & \end{array}$

\section{References}

Ahland, Colleen A. 2004. Linguistic variation within Gumuz: A study of the relationship between historical change and intelligibility. Arlington, TX: University of Texas at Arlington MA thesis.

Ahland, Colleen A. 2012. A grammar of northern and southern Gumuz. Eugene, OR: University of Oregon $\mathrm{PhD}$ dissertation.

Innocenti, Marco. 2010. Note elementary di grammatical Gumuz. Addis Ababa: Arada Books.

Loos, Eugene E. (gen ed.), Susan Anderson, Dwight H. Day Jr., Paul C. Jordan, \& J. Douglas Wingate (eds.). 2004. What is the hypothetical mood? In: Glossary of linguistic terms. http://www-01.sil.org/linguistics/GlossaryOfLinguisticTerms/WhatIsHypotheticalMood.htm. (11 August, 2015).

Payne, Thomas E. 1997. Describing morphosyntax: A guide for field linguists. Cambridge: Cambridge University Press.

Taylor, John R. 1997. Conditionals and polarity. In: A. Athanasiadou et R. Dirven (eds.) On conditionals again. Amsterdam: John Benjamins, 289-306.

Thompson, Sandra A., Robert E. Longacre \& Shin Ja J. Hwang. 2007. Adverbial clauses. In: Timothy Shopen (ed.) Language typology and syntactic description, vol.2: Complex constructions (2nd edn). Cambridge: Cambridge University Press, 237-300. 
Uzar, Henning. 1989. Studies in Gumuz: Sese phonology and TMA system. In: M. Lionel Bender (ed.) Topics in Nilo-Saharan linguistics, 347-383. Hamburg: Helmut Buske Verlag.

Travis Williamson travis_williamson@sil.org
Submitted: 17 August 2015

Accepted: 9 March 2016

Revisions: 28 March 2016 